\title{
TRILHAS DE UM DEBATE CONTEMPORÂNEO: RURALIDADES, CAMPESINATO, NOVO NOMINALISMO
}

TRACKS OF A CONTEMPORARY DEBATE: RURALITIES, PEASANTRY, NEW NOMINALISM

Maria Dione Carvalho de Moraes* Doutorado em Ciências Sociais/Universidade Estadual de Campinas Professora da Universidade Federal do Piauí

E-mail: mdione@ superig.com.br Teresina, Piauí, Brasil

Sérgio Luiz de Oliveira Vilela Doutorado em Ciências Sociais/Universidade Estadual de Campinas Pesquisador III da Empresa Brasileira de Pesquisa Agropecuária E-mail: svilela13@yahoo.com.br Teresina, Piauí, Brasil

*Endereço: Maria Dione Carvalho de Moraes

Universidade Federal do Piauí, Centro de Ciências Humanas e Letras, Departamento de Ciências Sociais. Ininga. Teresina/PI, Brasil.

Editora: Dra. Marlene Araújo de Carvalho

Artigo recebido em 12/02/2013. Última versão recebida em 10/03/2013. Aprovado em 11/03/2013.

Avaliado pelo sistema Triple Review: a) Desk Review pela Editora-Chefe; e b) Double Blind Review (avaliação cega por dois avaliadores da área). 


\title{
RESUMO
}

O pensamento brasileiro sobre o rural, na atualidade, debate temas como ruralidades/urbanidades, teorias de campesinato/novos nominalismos, com indícios de um movimento teórico de crítica e desconstrução de metanarrativas e do próprio conceito de camponês nelas fundado, frente à emergência de um novo nominalismo. Novas configurações da vida social provocam modulações significativas na construção conceitual de rural e urbano, de modo que as dimensões geográficas, socioeconômicas, culturais, naturais, específicas, são tomadas, cada vez mais, relacionalmente. A discursividade teórica de "rural" como categoria do pensamento enfrenta mudanças socioeconômicas, demográficas, culturais, que levam a se pensar campo, cidade e sua relação com representações do espaço rural extrapolando características paisagísticas e formas de uso dos bens naturais, para além de uma base físicoespacial, e como forma de percepção e representação cultural e identitária. Rural e urbano, longe de se oporem como espaços geográficos ou de realização de determinadas atividades, são pensados como construções simbólicas. Neste contexto, torna-se incontornável a reflexão sobre direções do texto brasileiro sobre ruralidades.

Palavras-chave: ruralidades; campesinato; novo nominalismo.

\begin{abstract}
The Brazilian thought about the countryside, in actuality, debate topics such ruralities / urbanities, theories peasantry / new nominalism, with indications of a theoretical movement of criticism and deconstruction of meta-narratives and the concept of peasant based on them, facing the emergence of a new nominalism. New configurations of social life cause significant modulations in the conceptual construction of rural and urban, so that the geographical dimensions, socioeconomic, cultural, natural, specific, are taken increasingly relationally. The theoretical discourse of "rural" as a category of thought faces changes socioeconomic, demographic, cultural, leading to think about the field, the city and its relation to representations of rural extrapolating landscape features and usage of natural resources, in addition to a based physical-spatial, and as a form of perception and representation and cultural identity. Rural and urban, far from precluding such geographical areas or performing certain activities, are thought of as symbolic constructions. In this context it becomes unavoidable reflection on directions in the text on Brazilian ruralities.
\end{abstract}

Key words: ruralities; peasantry; new nominalism. 


\section{INTRODUÇÃO}

O chamado meio rural brasileiro, como lembra Maria Isaura Pereira de Queiroz, tornou-se objeto de estudos da passagem do século XIX para o século XX, com autores como Sylvio Romero e Euclides da Cunha, persistindo neste, com Oliveira Vianna, Gilberto Freyre, Monteiro Lobato, Caio Prado Jr., Antônio Cândido, Manoel Correia de Andrade, dentre outros. Tais estudos demarcaram importante inflexão: “[...] ao contrário do que antigamente se pensava, havia pelo menos mais uma camada social rural, além dos fazendeiros e da mãode-obra sem terra - camada intermediária formada pelos sitiantes” (QUEIROZ, 1973, p. 14). Podemos tomar esta remissão como um momento fundante do que Ferreira (2008) chama de “Texto Brasileiro (TB)" sobre o rural ${ }^{1}$, denominação com função heurística na pesquisa que dá origem a este artigo.

Um século depois dos inícios da inflexão referida por Queiroz (1973), considerando-se seu amplo desdobramento em uma vasta e qualificada produção sobre o rural brasileiro e suas populações, como este texto brasileiro se apresenta, na atualidade? Sem pretensão de um exame exaustivo, focalizamos alguns elementos relacionados ao pensamento teórico nativo sobre o tema, em especial, no que tange a sentidos contemporâneos das ruralidades e populações rurais.

O contexto de rápidas mudanças mundiais, na contemporaneidade, inclusive, no Brasil, interpela o debate atual sobre o chamado "mundo rural" a um repensar das configurações materiais e simbólicas de rural e urbano, suas relações, e seus viventes. Como analisa Brumer (2003), quando fala dos rumos do rural na América Latina, tudo isto se dá em um cenário de grandes transformações sociais, econômicas e políticas do início do século XXI. Isto envolve novas fronteiras agrícolas, áreas pioneiras, santuários ecológicos, pólos de crescimento dominados pelo agronegócio, pólos de desenvolvimento rural integrado, de desenvolvimento local, zonas de contato interétnico, lugares de tradições campesinas, comunidades e populações tradicionais, de (re)assentamentos humanos, modos de vida, migrações. Fenômenos interpretados por olhares e discursos de variados matizes. (MORAES, 2011).

O debate é pautado pelo imperativo de mudanças nos modelos de desenvolvimento vigentes. A mirada de estudos e pesquisas desencadeados nos anos 1990 e interpelados pelo

\footnotetext{
${ }^{1}$ Ferreira (2008) baseia-se nos conceitos de Texto Brasileiro de Daniel Lins, em 1993, e de Texto Ocidental de Legendre, de 1974 
fenômeno da globalização ou mundialização, em sua múltiplas dimensões ${ }^{2}$, vem repondo na arena política e teórica, conceitos como espaço, território, territorialidades, territorialização, (des)territorialização, (re)territorialização. De forma correlata, vêm sendo repensadas as relações entre campo e cidade, cujos processos sociais, políticos, econômicos, culturais, ambientais, envolvem atores sociais nas dimensões de .gênero, etnia, geração, visões de mundo, modos de vida, com desafios epistemológicos, teóricos, e empíricos, correlatos.

Interpelado por novas configurações da vida social, o texto brasileiro sobre rural debruça-se sobre ruralidades/urbanidades, teorias de campesinato/novos nominalismos. No movimento teórico de crítica, desconstrução, reconstrução divergências e convergências, aponta-se para novos desafios. Extrapolando significados da construção conceitual de rural e urbano como espaços geográficos, socioeconômicos, culturais, naturais, específicos, observam-se na geografia, na economia, nas ciências sociais stricto senso, modulações significativas nas formas de pensar estas realidades, cada vez mais, relacionalmente.

A partir de pesquisa sobre imagens e narrativas do rural na produção acadêmica da UFPI (MORAES e PEREIRA, 2010) ${ }^{3}$, realizamos, neste artigo, uma hermenêutica textual. O foco não são ruralidades, campesinatos, campesinidades, ou novos nominalismos, tratados empiricamente, mas como estas categorias analíticas são acionadas, no texto brasileiro, para pensar realidades, ao mesmo tempo que as co-constrói. Alinhavamos elementos teóricos da reflexão socioantropológica, com algumas referências a pesquisas realizadas/realizando-se no Piauí, em registros variados, relacionadas ao debate contemporâneo das referidas temáticas. Sem pretender uma exegese exaustiva das idéias que circulam no campo abordado ${ }^{4}$, limitamonos a referir algumas linhas de pensamento, partindo de enunciações privilegiadas sobre o assunto.

\footnotetext{
2 Appadurai (1994) localiza o problema central das interações globais atuais na tensão entre tendência à homogeneização e à heterogeneização cultural, como duas faces de uma mesma moeda. A nova economia cultural global, uma ordem disjuntiva, superposta e complexa, apresenta disjunções fundamentais entre economia, cultura e política, cuja estrutura elementar pode ser pensada em cinco dimensões: "etnopanoramas"; "tecnopanorama"; "midiapanoramas" e "ideopanoramas". Para detalhes, ver Appadurai (1994).

${ }^{3}$ No texto piauiense sobre o rural, temas da problemática do desenvolvimento e da questão social são tratados a partir dos processos de mudança social em curso, no Piauí, nas últimas décadas, por autore/as implicado/as com uma realidade da qual participam como obbservadore/as interessado/as. (MORAES, 2011).

${ }^{4}$ Campesinato como objeto de reflexão é um legado de cientistas sociais, desde os estudos de comunidades. Foge aos objetivos deste artigo uma abordagem histórica destes olhares (NEVES, 2009)..
} 


\section{REFERENCIAL TEÓRICO-METODOLÓGICO}

\section{Alinhando conceitos}

Pensar sobre como concebemos o rural e suas populações, leva a uma remissão ao pensamento de Henri Léfèbvre sobre o tema, a partir da análise de três modelos clássicos de pensamento sobre o rural: 1/ na França, como "audacioso rapto ideológico ${ }^{5}$ [com] preocupações e objetivos da burguesia que alcançou o poder" (LÉFÈBVRE, 1986, p. 147), e com uma contribuição da escola de geografia humana, embora marcada por certo "geografismo um tanto estreito" (pp.148-149); 2/ nos EUA, como um ramo da sociologia geral, uma sociologia de "caráter ao mesmo tempo descritivo e normativo" (p. 150), 3/ na União soviética, como um "estudo da realidade camponesa [no qual] une-se, necessariamente, ao esforço para transformar esta realidade ${ }^{6}$, isto é, a teoria econômica à política" (p.150)

No caso brasileiro, Martins $(1975,1986)$ refere "esquemas teóricos de cunho dualista" (MARTINS, 1986, p. 11). Nestes, o rural foi pensado como parte de um continuum, ou pela oposição rural-urbano, havendo necessidade não apenas de ultrapassar os limites da dualidade, mas também de debruçar-se sobre sua gênese teórica e histórica. $O$ autor aproxima-se à análise de Mannheim (1986) sobre estilos de pensamento (conservadorismo e racionalismo), e de Nisbet (1986) sobre pares de idéias-elementos opostas, com origem nos séculos XVIII e XIX, e que correspondem à relação antitética conservadorismo/racionalismo: "comunidades/sociedade, autoridade/poder, status/classe, sagrado/profano, alienação/progresso", (MARTINS, 1986, p. 17). Fala da "ambiguidade de origem" da sociologia (p. 18) para perguntar como opera e frutifica esta ambigüidade no pensamento sociológico sobre o rural.

Na produção discursiva contemporânea, para além dos esquemas dualistas, o rural e as populações rurais (WANDERLEY, 2002) tendem a ser pensados com modulações analíticas sobre ruralidades, no plural, e não mais sobre "o rural" no singular (CARNEIRO, 2002; 2012). Esta inflexão aponta para uma abordagem na perspectiva territorial (SARACENO, 1994; ABRAMOVAY, 1999), tomando ruralidades e urbanidades como fenômenos que incorporam racionalidades locais que se apresentam, espacialmente, cada vez mais difusas

\footnotetext{
5 "O rapto ideológico, a tradução de uma noção segundo significações que são estranhas à sua extração original, constitui uma possibilidade constante, provavelmente inerente ao processo objetivo de produção do conhecimento sociológico" (MARTINS, 1986, p. 22)

${ }^{6}$ Um paralelo com o chamado pragmatimo,o "fonte filosófica da Escola de Chicago" (JOAS, 1999, pp. 127)

${ }^{7}$ Sobre antinomias originadas do grande paradigma ocidental, ver Morin (2001).
} 
não mais vistas como correspondendo a realidades distintas cultural e socialmente (CARNEIRO, 2002), em que pesem particularidades de cada uma dessas espacialidades sócio-simbólicas.

Para Wanderley (2002), ressemantiza-se a idéia de continuum rural-urbano como expressão de relações entre dois pólos que se interrelacionam. $\mathrm{Na}$ análise desta configuração, Wanderley (2011) propõe o exame de quatro dimensões: 1/ a moderna questão fundiária, com o foco nas implicações da escolha social entre as alianças da propriedade da terra, por um lado, com o capital, por outro, com o trabalho; 2/ o progresso técnico e a oposição entre as concepções: industrialização da agricultura X gestão dos seres vivos; 3/ o lugar do campesinato na contemporaneidade: elemento residual, em vias de desaparecimento ou potencializador de novas responsabilidades?; 4/ os sentidos do rural entre modelos de urbanização do campo e de desenvolvimento rural sustentável.

A discursividade teórica relativa ao rural como categoria do pensamento contempla mudanças socioeconômicas e demográficas nas representações do campo, da cidade, e das relações recíprocas. E o espaço identificado como rural extrapola características paisagísticas e formas de uso dos bens naturais, sendo pensado, para além de uma base físico-espacial, como forma de percepção e representação cultural e identitária. Concepções de rural/urbano, longe de referir espaços geográficos ou de realização de determinadas atividades, tomam-nos como construções territoriais, em suas dimensões materiais e simbólicas.

Busca-se apreender sentidos das transformações decorrentes de processos sociais e econômicos mais gerais os quais reconfiguram espacialidades regionais em cujo âmbito diversidade e heterogeneidade de espaços rurais/urbanos são forjadas por: descentralização econômica e política, novas tecnologias informacionais, fluxos de comunicação e interação. Em larga medida, tais mudanças relacionam-se à crise instaurada pelos limites do modelo dominante de desenvolvimento, dando corpo à reflexão nos marcos do que se convencionou chamar desenvolvimento sustentável, desenvolvimento territorial, desenvolvimento local ${ }^{8}$.

No que tange ao tratamento teórico de populações rurais e/ou "urbanas" (CARNEIRO, 1998), observam-se, ao lado do conceito de camponês (WOORTMANN, K. 1990; GODOI, 1990; WOORTMANN, E. 1995; WANDERLEY; 1996; MORAES, 2000; 2009, BRANDÃO, 2007, dentre outro/as) e de campesinidade (WOORTMANN, K, 1990) ${ }^{9}$, inflexões que

\footnotetext{
${ }^{8}$ Sobre a temática, ver Ribeiro (1992); Viola, et al. (2001); Redcliff (2002); Camargo, Capobianco; Viola (2001); Cavalcanti ( 2003).

${ }^{9}$ Estas abordagens, longe de mera abstração conceitual, insistem na necessidade de se considerarem formas concretas de existência material simbólica dos diversos campesinatos. A propósito, ver Garcia e Heredia (2009).
} 
apontam para a crise paradigmática das teorias do campesinato, e para um novo nominalismo (ALMEIDA, M. 2007).

Para Almeida, M. (2007), trata-se do fim de uma imagem de campesinato como fato social total no interior de uma história universal e, ao mesmo tempo, de novas pistas sobre a vitalidade de temáticas outrora subsumidas nos discursos sobre rural e campesinato. Pensar sobre esse novo nominalismo leva à remissão da literatura socioantropológica nos anos 1980, quando se observou na cena política, com reverberações na teoria, uma explosão de movimentos sociais e marcadores identitários ${ }^{10}$.

Nos anos 1990, ganha a cena política e teórica o conceito operacional de agricultura familiar (LAMARCHE, 1993, 1994, MORAES, 1998, NEVES, 1998), seguido por "antropologias ad hoc": da floresta, do sertão, do mar, etc. (ALMEIDA, M. 2007), pela categoria "rurbano" (CARNEIRO, 1998; VEIGA et al, 2001), enfim, por uma plêiade de identificações político-conceituiais: populações/povos tradicionais (como indígenas, quilombolas, fundos de pasto); agricultores camponeses, pequenos proprietários, expropriados da terra, diaristas, volantes, peões de fazendas, acampados de beira de estrada, assentados de reforma agrária, cortadores de palha de carnaúba, quebradoras de coco babaçu, povos dos cerrados, pescadores (BRANDÂO 2007, ALMEIDA, W, 2009; ALMEIDA, W. e MARIM, 2007; MORAES, 2009, VILELA e MORAES, 2008, MORAES e VIELLA, 2010; MARTINS e MORAES, 2010; MORAES e MARTINS 2011) ${ }^{11}$, dentre outras.

Esta pluralidade de categorias êmicas e éticas na referência a populações rurais/urbanas, lembra o que diz Martins (1975), retomado por Brandão (2007), sobre a pequena unidade camponesa não ser marginal, mas organicamente funcional à expansão do capitalismo no campo. No processo, formas múltiplas de existência emergem/recriam-se na fricção sujeito/estrutura, em suas singularidades.

\section{Bases espistemológica e operacional da pesquisa: etnografando o texto brasileiro sobre ruralidades}

Em consonância com o exposto, a base das reflexões aqui desenvolvidas é pesquisa documental (CELLARD, 1997; SPINK, 2000; MAY, 2004) de cunho bibliográfico. Trata-se de uma etnografia textual (SOUSA, 1997), em uma perspectiva antropológica "para além do trabalho de campo" (GIUMBELLI, 2002. p. 91).

\footnotetext{
${ }^{10}$ Ruben (1986) refere o processo, nos anos 1980, com referência à teoria da identidade.

${ }^{11}$ As referências, incluindo estudos realizados no Piauí, não são exaustivas, mas consideradas, dentre outras.
} 
Concordamos com Wolf (2003) que definições não devem ser tomadas como verdades eternas, mas como ferramentas do pensamento. E na ciência, campo agnóstico e controverso, um artigo científico pode provocar transformações em tipos de enunciados - caso, por exemplo, do conceito de camponês, como dizem Shanin (1980), Wolf (2003) e Almeida, M. (2007), em perspectivas não exatamente convergentes - assim como as várias posições constitutivas dos campos (BOURDIEU,1987,1989) definem possibilidades de um argumento produzir determinados efeitos. Bourdieu, Chamboredon, e Passeron (2004) reafirmam algo que não se pode escamotear: o objeto, na pesquisa científica, é construído.

Como dito por Mirim (2000), com base em Mikhail Bakhtin, enunciações, mesmo imobilizadas na escrita, são construídas como respostas a algo. Produzidas para serem compreendidas, elas orientam-se para leituras, historicamente situadas, seja na escrita científica, literária, ou em outras linguagens (cinema, música, teatro, etc). Como isto se apresenta no âmbito da literatura especializada, nas Ciências Sociais, cujo objeto é "o rural" e suas populações, em abordagens e interpretações diversas, é temática passível de submissão a uma hermenêutica textual (HABERMAS, 2009) de imagens e narrativas de ruralidades, e de populações rurais/urbanas.

A produção discursiva da ciência circula através de um complexo sistema de comunicação formal regido por estratégias de validação consagradas pela tradição ou pelas hierarquias, em posições muitas vezes concorrentes. A validação institui construtos e filiações epistemológicas e teóricas apontando para a idéia de paradigma (KUHN, 2003, MORIN, 2001). Sem esquecer que formas retóricas de enunciação do texto científico (COLOMBO, 2005) constituem, em si mesmas, não apenas estilos mas compromissos teórico-epistemológicos.

No campo da cientificidade, visto pela ótica da prática de grupos específicos, desenvolvem-se linguagens sociais particulares com regras próprias de construção e de apresentação (MIRIM, 2000). As palavras provocam a busca de compreender sentidos e transformações sutis nos termos e expressões construídos socialmente. Hermeneuticamente, isto se relaciona a uma capacidade na arte de compreender (GEERTZ, 1986), de modo a contemplar conteúdos semânticos dos discursos, no caso, significados fixados por escrito (SOUZA, 1987; SPINK, 2000). 


\section{RURALIDADES E POVOS RURAIS NO TEXTO BRASILEIRO (RESULTADOS E DISCUSSÃO)}

Fim do rural? Morte do campesinato? A reflexão nativa sobre rural e campesinato atravessa, no sentido de Santos (1989) uma crise de crescimento ou de degenerescência? Na atualidade, a literatura socioantrpológica, em largos traços, tende a considerar que construtos teóricos sobre ruralidades e populações rurais requerem releituras. Indícios de manifestações associadas a ruralidades apresentam-se nas práticas sociais através de atores individuais e coletivos, e instituições. Populações rurais são pensadas seja na perspectiva teórica de campesinato, seja na mirada à crítica desta teoria - como metanarrativa que não dá conta da diversidade empírica de sujeitos rurais/urbanos - pela lente do novo nominalismo. Diálogos?

\section{Sobre a temática ruralidades}

Realinhamentos teóricos apontam para a ultrapassagem das extremas conjeturas sobre completa urbanização ou renascimento rural. Observa-se uma inflexão no sentido de questionar construtos de um continuиm urbano-rural como pólos assimétricos e inconciliáveis, com um deles tendendo a eliminar o outro. Ruralidades e urbanidades são vistas como conteúdos sociais de práticas socioculturais e políticas, incorporadas no curso da vida dos atores sociais, nas instituições, nos agentes coletivo. Ambas ruralidades/urbanidades - são tomadas como representações de diferentes universos simbólicos de indivíduos e grupos.

O debate sobre o chamado mundo rural modula-se na direção de se repensarem sentidos das relações entre rural e urbano, e populações rurais. Wanderley (2011) destaca quatro processos, aqui referidos, em diálogo com autores e idéias convergentes, os quais, nas últimas décadas desdobram-se em consequências definitivas para o que se considera rural brasileiro, e por extensão, piauiense: 1/ avanços científicos, sobretudo na genética e na ecologia, reforçando as críticas políticas à perspectiva produtivista de progresso; 2/ avanços na consciência da necessidade de preservação da biosfera, incluindo-se a própria vida e sociedades humanas, no planeta; 3/ conquistas tecnológicas no campo da comunicação humana, com a emergência do que Castells (2000) denomina "sociedades em redes", quer no plano interno das sociedades nacionais, quer na interface destas sociedades no processo de mundialização; 4/ ampliação e aprofundamento das democracias com as conseqüentes expressões de demandas pelo direito à cidadania e o conseqüente direito à diversidade social, 
apontando para lutas diversas que refletem o que Oliveira (2006, p. 19) concebe como "moral do reconhecimento".

No Brasil, sobretudo, a partir das duas últimas décadas do Novecentos, olhares diversos apontam para novas temáticas e abordagens, em largos traços, em dois campos discursivos complementares.

No primeiro, a definição do espaço rural não exclusivamente pela atividade agrícola (SILVA, J. G.. 1999, WANDERLEY, 2002, CARNEIRO, 2002, VILELA, 2000b), incluindo o fenômeno da pluriatividade como movimento de reorientação produtiva de populações residentes no campo; novas formas de organização da atividade agrícola como alternativa a deixar o campo, ao desemprego urbano, e ao padrão de desenvolvimento agrícola dominante (CARNEIRO, 1996, SCHNEIDER, 1999); a multifuncionalidade da agricultura e dos territórios, territorialidades e "ruralidades"; cidades e seu entorno (CARNEIRO e MALUF, 2003). Limites dos conceitos de "meio rural" ou "sociedade rural" (CARNEIRO, 2002, WANDERLEY e LOURENÇO, 1994). Some-se o movimento identificado como neoruralismo, que ganha corpo no Brasil a partir dos anos 1970, expandindo-se e encontrando legitimidade na divulgação do pensamento ecológico. Traduz-se na procura crescente de formas de lazer associadas ao rural e de meios alternativos de vida no campo, por citadino/as, com novas possibilidades de trabalho para a população rural, e uma maior aproximação e integração de sistemas culturais distintos. (GIULIANI, 1990).

No segundo, reflexões sobre populações rurais (WANDERLEY, 2000), com relações conceituais entre campesinato e agricultura familiar (LAMARCHE, 1993; 1994, NEVES, 1998 WANDERLEY, 19966; MORAES, 1998); campesinato e povos tradicionais (PAOLIELLO; 2009; RUBERT e SILVA, 2009) ${ }^{12}$; campesinato e capitalismo (MARTINS, 1975; FERNANDES, 2004). Neste campo, a crítica aos limites das teorias do campesinato (WOORTMANN, 1995, FERREIRA, 2008); reflexões sobre a morte das teorias do campesinato e a emergência de um novo nominalismo (ALMEIDA, 2007); a busca de articulação do conceito de campesinato a novos nominalismos (BRANDÃO, 2007; MORAES, 2011).

O texto brasileiro reflete manifestações de ruralidades que, no campo e na cidade, presentificam-se em múltiplas dimensões: econômica, política, cultural. Na economia, práticas agropecuárias orientadas pelo padrão da agricultura moderna, da "tradicional" ou de produção orgânica, no campo e na cidade; turismo rural; mercados futuros de commodities

\footnotetext{
${ }^{12}$ Em diálogos teóricos com o conceito de condição camponesa de Bourdieu (1962).
} 
em espaços citadinos; economias camponesas. Na política, personalismo; clientelismo; corporativismos no mercado internacional acerca de subsídios agrícolas; disputas no âmbito das instituições públicas, como Ministérios da Agricultura e do Desenvolvimento Agrário no Brasil; movimentos sociais diversos; multifuncionalidade das agriculturas familiares. $\mathrm{Na}$ cultura, reaproximação da natureza por citadinos; hábitos de origem country; músicas sertanejas, expressões culturais diversas: rituais de vida e de morte, festas, funerais, religiosidade, gastronomia, além dos desafios da articulação entre políticas culturais e de desenvolvimento ${ }^{13}$, etc.

Por seu turno, urbanidades apresentam conteúdos multidimensionais que extrapolam limites geográficos entre campo e cidade, sendo esta não mais compreendida sem o seu entorno: na economia: complexa divisão social do trabalho, redes técnicas, transporte e comunicação; diversificação de atividades: agrícolas e não-agrícolas. $\mathrm{Na}$ política: planejamento e gestão de território e crescente normatização dos usos dos espaços citadinos e campestres. Na cultura: emancipação feminina, redução da divisão sexual do trabalho, fluidez de informação, estetização de comportamentos, sobretudo juvenis, principalmente através das mídias, etc.

Os próprios limites do modelo produtivista, no campo, e da expansão industrial nas cidades, a partir dos anos 1980, fazem emergir formas alternativas de reprodução nos espaços rurais/urbanos, indicando a necessidade de cautela nas generalizações e de reconsiderar a relação entre tradições culturais e modernização da agricultura. Nem espaços rurais vivem um processo único de transformação, nem medidas modernizadoras sobre a agricultura, no padrão de produção e de vida urbano-industrial, uniformizam efeitos sobre populações locais nem suas reações. (CARNEIRO, 2002).

Ruralidades delineiam funções de uma cidade e vice-versa. A urbanização pode revelar-se corporativa, personalista e/ou comprometida com interesses do agronegócio na difusão de ruralidades na cidade, promovidos por agentes detentores dos meios de produção caso, por exemplo, dos impactos da incorporação agrícola dos cerrados do sudoeste piauiense (MORAES, 2000) nas pequenas e médias cidades da região. Por outro lado, populações que não dominam o saber moderno podem, também, gerar transformações e novas relações campo/cidade. Agricultores "tradicionais" em movimentos de reconversão produtiva, em processos de novas identidades socioculturais (ou ruralidades) ${ }^{14}$ no campo e na cidade, caso

\footnotetext{
${ }^{13}$ A dimensão cultural em programas de desenvolvimento rural é tema de pesquisa iniciada por Moraes ( 2013).

${ }^{14}$ Carneiro (2002) refere situação recente na Alemanha Ocidental, com a cultura camponesa tradicional formulando saídas para a crise da economia e do ecossistema. Para Shanin (2008) camponeses absorvem e acompanham a dinâmica da sociedade envolvente,
} 
da apicultura piauiense (VILELA, 2000a), da agricultura familiar do Vale do Gurguéia-PI (PEREIRA, 2004) ou, ainda, de populações quilombolas, pelo auto-reconhecimento e afirmação da territorialidade (SOUSA, PEREIRA, PAZ, 2010; MATOS, 2013). Atividades não-agrícolas e pluriatividade de famílias rurais ${ }^{15}$, apontam para a multifuncionalidade de famílias e territórios (MALUF et al, 2002, ABRAMOVAY, 2002, CAZELLA e MATTEI, 2002, MORAES e VILELA, 2003). Pesquisas sobre um "novo rural” (SILVA, J. G. 1999, CARNEIRO, 2002; VILELA, 2002a; 2002b.) e sobre ruralidades contemporâneas e as novas relações rural/urbano (CARNEIRO, 2012; FAVARETTO; 2007), incluem-se nesta pauta. Somem-se experiências diversas de agricultura urbana como política de desenvolvimento territorial (FAO, 1999; GNAU, 2020; ROSA, 2011; MINISTÉRIO DO DESENVOLVIMENTO SOCIAL E COMBATE À FOME; SECRETARIA NACIONAL DE SEGURANÇA ALIMENTAR E NUTRICIONAL, 2011;VILELA E MORAES, 2013).

Por seu turno, urbanidades delineiam novas ruralidades, a exemplo da cidadania (DAGNINO, 2004) de populações rurais, conquistada/reconhecida, muitas vezes, com acesso a políticas públicas de transferência de renda; de proteção social a situações de trabalho não ou precariamente - contempladas pela legislação trabalhista ou de seguridade social; reconhecimento de territórios de povos tradicionais, dentre outras.

No Estado do Piauí, onde, pelo próprio processo mais tardio de modernização agrícola - se comparado a outros estados brasileiros - antigas e novas ruralidades convivem em sincronicidade, estudos como os de Moraes (2000; 2002; 2006); Pereira (2004); Silva (2011); Nascimento (2013); Moraes e Pereira (2010) apontam para dimensões diversas das ruralidades piauienses.

Citando situações estudadas na última década ${ }^{16}$, lembramos pesquisas sobre: campesinato dos cerrados do sudoeste piauiense (MORAES, 2000; MORAES e VILELA, 2003; 2006); dos "Bamburristas" de opala em Pedro Segundo (LIMA, 2008); assentamentos rurais, focalizando: identidades (COSTA, 2006); sustentabilidade (OLIVEIRA, 2013); a festa camponesa, pela expressão cultural do Bumba-meu-boi (SANTOS e MORAES, 2012) ${ }^{17}$;

\footnotetext{
adaptando-se a novas estruturas, com valores e organização social próprios. Fala de recentes processos de recampesinação no Brasil, e de migrações temporárias internacionais, na Europa, em busca de trabalho.

${ }^{15}$ Pelo peso de atividades não-agrícolas na dinâmica econômica e na composição da renda familiar (CARNEIRO, 1996, SILVA, J. G., 1999, SCHNEIDER, 1999); papel da agricultura e demais atividades na manutenção e criação de novos empregos e na geração de dinâmicas territoriais de desenvolvimento (ABRAMOVAY, 1999, VEIGA, et al, 2001, MORAES, 2002); produção, processamento, transformação e venda de produtos agrícolas de qualidade, em nichos de mercado (VILELA, 200a; 2002); proteção do meio ambiente e da biodiversidade (ROMEIRO, 2000, GUIVANT, 1994); segurança alimentar (MALUF, 1995, 2001, 2002); novas atividades relativas aos usos da paisagem, como o turismo rural (MATTEI, 2000, ARAÚJO e MARQUES, 2000).

${ }^{16}$ No caso, pesquisas realizadas pelo/as autore/as deste artigo, ou das quais a autora participou como orientadora ou co-orientadora em dissertações e teses.

${ }^{17}$ Com uma dissertação de mestrado e um livro, em curso, pela ótica da festa camponesa (PRADO
} 
campesinato e questão ambiental (SOUZA, 2005) quebradeiras e catadore/as de coco babaçu (VILELA e MORAES, 2008); de "”palheiros" de carnaúba, no Piauí (MORAES e VILELA, 2010; MARTINS e MORAES, 2010; MORAES e MARTINS, 2011; MARTINS, 2012); migrações temporárias temporários do Piauí para a agroindústria canavieira paulista (MORAES; FRAZÃO FILHO; ROGÉRIO JR., 2007); Migrações temporárias e Pronaf (FRAZÃO FILHO, 2009); Migrações temporárias e adoecimento (ROGÉRIO JR., 2010); povos camponeses atingidos pelo rompimento da Barragem Algodões I (OLIVEIRA, M. 2013); meio ambiente de trabalho e disciplinamento do corpo camponês em fazendas dos cerrados piauienses (REIS, 2010; REIS e MORAES, 2011. MORAES e REIS, 2012. REIS e MORAES, 2012), trabalho infantil entre populações rurais (REIS, 2012); presença de trabalho escravo em fazendas do agronegócio, no Piauí (MASULO, 2013).

São registros que apontam para o questionamento, cada vez mais presente na cena política nacional, regional e piauiense, das relações de patronagem-dependência ou tutelagem (FORMAN, 19779, NEVES 2008; 2009), marcadas, sobretudo, por reciprocidades verticais (MENESES, 2000), por problemas no meio ambiente de trabalho (REIS e MORAES, 2011). Neste âmbito, debatem-se conceitos e práticas relativos a direitos ao chamado trabalho decente $^{18}$. No processo, as relações entre urbanidades e ruralidades passam a ser vistas, cada vez mais, pela ótica territorial, ressemantizando a idéia de continuum, tomando-se rural e urbano como lugares materiais e simbólicos que se alimentam/tensionam, recíprocamente.

São reflexões sobre ruralidades contemporâneas, as quais veem-se interpeladas por novas questões teóricas, na construção de evidências empíricas. Cada uma delas contribuindo, a seu modo, no processo de construção do texto brasileiro sobre ruralidades e populações rurais na contemporaneidade.

\section{Sobre teorias do campesinato e novo nominalismo}

No que tange a povos rurais, no Brasil, nomes e obras demarcam uma tradição de algo em torno de meio século de estudos e pesquisas, em registros variados, voltados à compreensão/explicação de povos de um chamado mundo rural. Sem determo-nos na análise destas contribuições, o que foge aos objetivos e limites deste artigo, lembramos que o debate contemporâneo é caudatário de gerações de intelectuais diversificadas e de idéias nem sempre convergentes

\footnotetext{
${ }^{18}$ Trabalho decente foi tema de Conferência Nacional em 2012. No Piauí, em 2011, ocorreram conferências preparatórias para a Conferência Estadual e esta própria. 
Nomes como Antônio Cândido, Guilherme Otávio Velho, Giralda Seyferth, Maria Isaura Pereira de Queiroz, Margarida Maria Moura, José Vicente Tavares dos Santos, Beatriz Heredia, Luiz Eduardo Soares, Afrânio Garcia Jr., Ellen Woortmann, Klaas Woortmann, José de Sousa Martins; Maria Nazareth Baudel Wanderley, Carlos Rodrigues Brandão, são incontornáveis em um estudo da reflexão teórica nativa sobre campesinato, pequena produção agrícola, agricultura familiar ${ }^{19}$. Suas contribuições abarcam um vasto campo temático: cultura caipira; cultura rústica; campesinato de fronteira; lógica camponesa; colonato; modos de vida; política; modo de produção; parentesco; herança; campesinidade; luta pela terra; questão agrária; migrações; subordinação ao capital; religiosidade; festas; saberes; relação com a natureza; agricultura familiar, dentre outros.

No debate contemporâneo, Fernandes (2004) refere a presença de paradigmas diversos, realçando sua dimensão política a partir das perspectivas: o "paradigma do fim do campesinato"; o "paradigma do fim do fim do campesinato"; o "paradigma da metamorfose do campesinato".

O modelo de interpretação do fim do campesinato apresenta duas leituras: uma delas baseada na diferenciação, no sentido de que a renda capitalizada da terra destrói o campesinato de modo que um pequeno segmento se transforma em capitalista e um grande segmento em trabalhadores assalariados. Uma segunda leitura direciona-se para a inviabilidade da agricultura camponesa no capitalismo (FERNANDES, 2004) ${ }^{20}$.

Para o autor, concebe-se que a diferenciação não determina o fim do campesinato, embora o capital, por meio da renda capitalizada da terra, aproprie-se da riqueza produzida pelo trabalho familiar camponês. No entanto, o capital alimenta-se desse processo e, em diferentes condições, a apropriação da renda capitalizada da terra se lhe torna mais interessante que o assalariamento, o que leva proprietários de terra e capitalistas a oferecerem terras em arrendamento ou condições para a produção nas propriedades camponesas. Arrendamento, compra e ocupação da terra, são, portanto, formas de recriação do campesinato em um constante processo de territorialização, desterritorialização, e e(re)erritorialização; de destruição/recriação. Nesse modelo interpretativo, campesinato é visto como importante forma de organização social para o desenvolvimento humano em diferentes escalas. Uma de suas vertentes volta-se para o crescimento do número de

\footnotetext{
${ }^{19}$ Sobre a trajetória conceitual de populações rurais, no Brasil, ver Moraes (1998).Ver Neves (2009) numa análise do legado dos cientistas sociais sobre constituição e reprodução do campesinato no Brasil.

${ }^{20}$ Os temas inviabilidade do campesinato no capitalismo, e diferenciação reportam à teoria marxista e a clássicos marxistas (KAUTSKY, 1980, LENIN, 1984).
} 
camponeses via política de reforma agrária e territorialização da luta pela terra, e outra para ações visando à manutenção do número de camponese/as. (FERNANDES, 2004) ${ }^{21}$.

Quanto ao que Fernandes (2004) denomina paradigma da metamorfose do campesinato, na última década do século $\mathrm{XX}$, este concebe o fim do campesinato mas não do trabalho familiar na agricultura, numa lógica dualista que opõe atrasado (camponês) $X$ moderno (agricultor familiar), tomando-se como moderno um padrão a ser atingido por camponês/as. Aqui, atualizam-se as idéias-elementos, dicotômicas, referidas por Nisbet (1986). No plano ideológico, este modelo "naturaliza" o processo de diferenciação gerada na produção da renda capitalizada da terra que delimita os espaços políticos de ação condicionada no interior das condições geradas pelo capital, as quais, no plano técnicoburocrático institucional, produz a seguinte categorização: agricultor familiar consolidado; agricultor familiar intermediário e agricultor familiar periférico, que se encontra na matriz da concepção do Programa Nacional de Fortalecimento da Agricultura Familiar-Pronaf ${ }^{22}$.

Entre a condição de periférico e a de consolidado, estaria o espaço político de existência camponesa no interior de uma lógica que considera apenas os incluídos no espaço do processo de diferenciação. Além de uma interface com a segunda vertente do paradigma do fim do fim do campesinato, o modelo teórico da metamorfose do campesinato fundamentase no capitalismo agrário ao contrário dos anteriores cuja ancoragem é a questão agrária ${ }^{23}$, como referido por Wanderley (2011).

Se uma das inflexões do discurso acadêmico sobre populações rurais pode ser observada na cada vez maior presença da expressão agricultura familiar nos estudos, pesquisas e debates, lembra Wanderley (1996) que, embora agricultura familiar não constitua categoria social recente nem categoria analítica nova nas ciências sociais, adquire abrangência que jamais tivera, sendo um conceito genérico que abrange formas sociais específicas, uma das quais o campesinato.

Por seu turno, críticas atuais às teorias do campesinato, no Brasil, vão da análise nos marcos das próprias teorias sobre os seus limites, à reflexão sobre o seu fim como modelo explicativo. Na primeira posição, Woortmann, E. (1995), por exemplo, aponta para limites das teorias de campesinato, no que tange à ausência, em autores clássicos, sobretudo da economia camponesa, das teorias de parentesco. Por seu turno, Woortman, K (1990) provoca

\footnotetext{
${ }^{21}$ O pensamento de Shanin (2008), autor cuja presença é significativa nos debates teóricos no Brasil, pode ser visto, também, pela perspectiva da recriação.

${ }^{22}$ A propósito ver Veiga et al (2001)

${ }^{23} \mathrm{O}$ primeiro fundamento tem-se desenvolvido a partir do princípio da superação que implica na luta contra o capital e na perspectiva da transformação da sociedade. O segundo desenvolve-se a partir do princípio da conservação das condições existentes da sociedade capitalista. (FERNANDES, 2004).
} 
inflexão importante ao refletir teoricamente, não propriamente sobre campesinato, mas sobre campesinidade. Em outro registro, Ferreira (2008) etnografa o texto brasileiro na critica à sua filiação ao ideário de uma sexualidade camponesa no singular, de acordo com o pretenso modelo ideal de parentela, na esteira de uma economia utilitarista.

Na segunda posição, Almeida, M. (2007) observa que, para além das teorias do campesinato, um novo nominalismo emerge na identificação de novos atores sociais que emergem na cena política, como povos ou comunidades tradicionais: seringueiros, quilombolas, ribeirinhos, caiçaras, pescadores, etc (BRANDÂO, 2007; ALMEIDA, W, e MARIM, 2007). Para Almeida, M. (2007), as teorias do campesinato mostram-se limitadas, como metanarrativa que se revela insuficiente para pensar as novas configurações das populações que pretende analisar.

Para além das posições referidas, exemplos como Brandão (2007), Paolilello (2009); Rubert e Silva (2009); Moraes (2000), sinalizam para possibilidades de diálogos entre teorias do campesinato e novos nominalismos.

\section{CONSIDERAÇÕES FINAIS}

Nesta breve incursão, apontamos para algumas trilhas de um pensamento contemporâneo no qual campo e cidade tendem a ser pensados, cada vez mais, como formas concretas que se materializam e compõem paisagens produzidas pela ação social, política e cultural de homens e mulheres, com suas inserções de classes, etnias, gêneros e gerações, como atores sociais cujas configurações atuais desafiam limites teóricos.

Nos limites deste artigo, problematizando a discursividade teórica nativa sobre rural e povos rurais, mais do que apresentar soluções a problemas de ordem teórica, traçamos um desenho da argumentação sobre urbano e rural tomados como representações sociais, conteúdos das práticas dos atores sociais, individuais e coletivos, os quais, em sua concreção, apresentam-se sob formas empíricas diversas, para além de um modo de produção, uma economia, relações de parentesco fundadas em um corpo funcional, não-desejante. Urbanidades e ruralidades combinam-se em recortes espaciais, territoriais: um local, uma micro, meso ou macro região; e no plano simbólico, nas representações. Da mesma forma, populações rurais, ou "urbanas" interpelam as teorias à decifração de novos enigmas teóricoempíricos.

Ruralidade, hoje, não é mais pensada no singular, nem somente a partir da expansão do mundo urbano-industrial mas, também, do consumo, pela sociedade urbano-industrial, de 
bens simbólicos e materiais e de práticas culturais reconhecidos como tendo origem no chamado mundo rural (CARNEIRO, 2002), práticas estas, seja no campo, seja nos centros urbanos, que requerem a interpretação dos seus significados, do ponto de vista dos agentes. $\mathrm{O}$ "campo" - como categoria genérica - passa a ser visto mais como lugar de vida (WANDERLEY, 2000), e menos como mero espaço de produção agrícola. É falência da visão dualista que opunha rural a urbano como realidades empiricamente distintas, definidas pela negação mútua, e com base em critérios meramente descritivos, em um paradigma que associa rural a agrícola e atrasado, e urbano a industrial e moderno.

Indicamos, ainda, que conceitos como campesinato, campesinidade guardam virtualidades explicativas não sendo, simplesmente, descartáveis frente a novas interpelações da realidade e nominalismos decorrentes. A paisagem textual - em diálogo com realidades empíricas - orienta e define filiações, no processo de construção de categorias, conceitos e significados, sem necessariamente jogar fora a criança junto com a água do banho. Parafraseando Wanderley (2011, p. 32), "cabe a nós, demonstrar a competência e a sensibilidade para apreender as "continuidades ocultas" e as "rupturas profundas". (citando Jollivet, 2001, p. 84) e, assim, consolidar o que se pode considerar uma teoria contemporânea do campesinato". Nesta perspectiva, o hardcore do programa de pesquisa (LAKATOS e MUSGARVE, 1979) das teorias do campesinato permanece capaz de dialogar com os novos nominalismos.

Finalmente, pensamos com Spink (2000), que definições resultam de decisões científicas debatidas em círculos especializados, revistas apropriadas e livros autorizados. No tema em questão, este é um caminho que vem sendo percorrido e com muito a percorrer. E, se não há respostas conclusiva para as questões aqui delineadas, resta-nos continuar a fazer perguntas, sobretudo, a respeito dos diálogos pertinentes ou impertinentes, subjacentes.

\section{REFERÊNCIAS}

ABRAMOVAY, R. Do setor ao território: funções e medidas da ruralidade no desenvolvimento contemporâneo (primeiro relatório de pesquisa). IPEA. São Paulo/Rio de Janeiro: IPEA, (Projeto BRA/97/013 - Inter-relações entre as transformações demográficas e a agenda social), 1999, $44 \mathrm{p}$.

ABRAMOVAY, R. Subsídios e multifuncionalidade na política agrícola europeia. Economia Rural, vol.40, n.2. 2002, p.235-264.

AlMEIDA, A. W. B.; MARIM, R. A. (coord.) Projeto Nova Cartografia a Social dos Povos e Comunidades Tradicionais do Brasil. FASCÍCULO 4 - Comunidades dos 
Pescadores e Pescadoras Artesanais Mostrando sua Cara, Vez e Voz, Submédio e Baixo São Francisco Brasília, março 2007 . 12 p. Disponível em: http://biblioteca.inga.ba.gov.br/phl82/img/arquivo/36_mma_04_pescadores_Artesanais.pdf.

Acesso em março/2008

ALMEIDA, M. W. Narrativas agrárias e morte do campesinato. RURIS, v. 1, n.2, Campinas: Unicamp, setembro/2007, pp 157-188.

ALMEIDA, W.Terras de preto, terras de santo, terras de índio: uso comum e conflito. In: GODOI, E. P.; MENEZES, M. A.; MARINA, R. A. (Orgs.) Diversidades de campesinatos: expressões e categorias. Vol II. Estratégias de reprodução social. São Paulo: Ed. Da Unesp/Brasília:NEAD, 2009, pp. 39-66

APPADURAI, A. Disjunção e diferença na economia cultural global. In: FEATHERSTONE, M. Cultura global nacionalismo, globalização e modernidade. Petrópolis: Vozes, 1994, pp. 311-128.

ARAÙJO, J. G. F.; MARQUES, M. A. F. Turismo rural como uma ferramenta do desenvolvimento rural: um estudo de pesque-pague numa área da Zona da Mata, Minas Gerais, Brasil. ANAIS... XXXVIII Congresso Brasileiro de Economia e Sociologia Rural, Rio de Janeiro: IRSA/SOBER, 2000, CD Rom.

BOURDIEU, P . Célibat et condition paysanne. Études rurales, $\mathrm{n}^{\circ}$. 5/6, Apr. - Sep., 1962, pp. 32-135 . Disponível em: http://www.jstor.org/stable/20120997. Acesso em $30 \mathrm{~d}$ abril de 2010

BOURDIEU, P. A economia das trocas simbólicas. 2. ed. São Paulo: Perspectivas, 1987,

BOURDIEU, P. O poder simbólico. Lisboa: DIFEL/Rio de Janeiro: Bertrand Brasil, 1989.

BOURDIEU, P.; CHAMBOREDON, J_C; PASSERON, J-C.. A construção do objeto. In: Ofício de Sociólogo. Metodologia da pesquisa na sociologia, Petrópolis: Vozes, 2004, pp. $45-72$

BRANDÂO, C. R. Tempos e espaços nos mundos rurais do Brasil. RURIS. V.1, n.1, Campinas: Unicamp março/2007, pp. 37-64

BRUMER, A. Dossiê: os rumos do mundo rural na América Latina no início do século XXI, num cenário de grandes transformações sociais, econômicas e políticas. Sociologias, Porto Alegre, ano 5, no 10, jul/dez 2003, p. 14-25.

CAMargo, A.; CAPOBianco, J. P. R.; Oliveira, J. A. P. (orgs.). Meio Ambiente Brasil. Avanços e obstáculos pós Rio 92. São Paulo: Estação Liberdade: Instituto Socioambiental. Rio de Janeiro: Fundação Getúlio Vargas, 2002

CARNEIRO, M. J. (coord.). Do "rural" como categoria de pensamento e como categoria analítica. In: Ruralidade contemporâneas. Modos de viver e pensar o rural na sociedade brasileira. Relatório final do projeto "Pluriatividade e Ruralidade: identidades sociais em construção". Rio de Janeiro, setembro de 2002, pp.5-23

CARNEIRO, M. J. (org.). Modos de viver e pensar o rural na sociedade brasileira. Rio de Janeiro: Mauad, 2012, 
CARNEIRO, M. J. O ideal rurbano: campo e cidade no imaginário de jovens rurais. In: SILVA, F.C.T.; SANTOS, R.; COSTA, L.F.C. (Org.). Mundo rural e política: ensaios interdisciplinares. Rio de Janeiro: Campus, 1998

CARNEIRO, M. J., MALUF. R. (org.). Para além da produção. Multifuncionalidade e agricultura familiar. Rio de janeiro: MAUAD, 2003,

CARNEIRO, M.J. Pluriactivité: l'hétérogénéité cachée. Cahiers d'Economie et Sociologie Rurales, 1996.

CASTELLS, M. O poder da identidade. São Paulo: Paz e Terra, 2000

CAVAlCANTI, C. (org.) Desenvolvimento e natureza: estudos para uma sociedade sustentável, São Paulo: Cortez, 2003, pp. 276-292

CAZELLA, A. A.; MATTEI, L. Multifuncionalidade agrícola e pluriatividade das famílias de agricultores: novas bases interpretativas para repensar o desenvolvimento rural. Florianópolis, ([2002])

CELLARD, A. A análise documental. In: A pesquisa qualitativa. Enfoques epistemológicos e metodológicos; Petrópolis: vozes, 1997, pp. 295-316

COLOMBO, E. Descrever o social - a arte de escrever a pesquisa empírica. In: MELUCI, A. Por uma sociologia reflexiva. Pesquisa qualitativa e cultura. Petrópolis: Vozes, 2005, pp. 265-288.

COSTA, C. M. S. B. De moradores a assentado/as: trajetórias e identidades sociais no Centro do Designo, em Miguel Alves, no Piauí. Dissertaçãa. Programa de Pós-Graduação em Políticas Públicas. Universidade Federal do Piauí. Teresina: UFPI, 2006

DAGNINO, E. “¿Sociedade civil, participação e cidadania: de que estamos falando?” In: MATO, D. (coord.), Políticas de ciudadanía y sociedad civil en tiempos de globalización. Caracas: FACES, Universidad Central de Venezuela, 2004, pp. 95-110.

FAO. issues in urban agriculture - Studies suggest that up to two-thirds of city and peri-urban households are involve in farming. Web page. FAO: http://www.fao.org/ag/magazine/9901ap2.ht, 1999.

FAVARETTO, A. A longa evolução da relação rural-urbano. Para além de uma abordagem Normativa do desenvolvimento rural. RURIS, v. 1, n. 1, Março de 2007, pp. 157-190

FERNANDES, B. M. Um referencial para o campesinato no Brasil (versão preliminar). Curitiba, maio de 2004. Disponível em: www.coptec.org.br/.../Campesinato\%20e\%20Reforma\%20Agrária. Acesso em janeiro/2005

FERREIRA, P. R. Os afectos mal-ditos: o indizível nas sociedades camponesas. São Paulo, Editora Hucitec/Fapesp, 2008.

FORMAN, S. Camponeses: sua participação no Brasil. Rio de janeiro: Paz e Terra, 1979.

FRAZÂO FILHO; F. Migração temporária e Pronaf: uma combinação estratégica na trajetória social de populações camponesas em Francinópolis- 
PI. Dissertação. Programa de Pós-Graduação em Políticas Públicas. Universidade Federal do Piauí. Teresina: UFPI, 2009.

GARCIA Jr., A. R.; HEREDIA, B. A. Campesinato, família e diversidade de explorações agrícola no Brasil. In: GODOI, E. P.; MENEZES, M. A.; MARIN, R. A. (orgs.) Diversidades de campesinatos: expressões e categorias. Vol II. Estratégias de reprodução social. São Paulo: Ed. da Unesp/Brasília:NEAD, 2009, pp. 213-243

GIULIANI, M. Neo-ruralismo: o novo estilo dos velhos modelos. 1990. Disponível emhttp://www.anpocs.org.br/portal/publicacoes/rbcs_00_14/rbcs14_05.htm. Consultado em 02/02/2010.

GIUMBELLI. E. Para além do "trabalho de campo": reflexões supostamente malinowskianas. Revista Brasileira de Ciências Sociais, vol. 17, n. 48, fev/2002, pp. 91107

GNAU-GRUPO NACIONAL DE AGRICULTURA URBANA. Lineamentos para los subprogramas de Agricultura urbana para el año 2002 y sistema evaluativo. Cuba : Ministério de Agricultura, 2002. 84 p.

GODOI, E. P. O trabalho da memória: cotidiano e história no sertão do Piauí. Campinas: UNICAMP, 1999, $165 \mathrm{p}$.

GUIVANT, J. S. Encontros e desencontros da sociologia rural com a sustentabilidade agrícola: uma revisão temática. In: BIB - ANPOC'S 38. Rio de Janeiro: Relume-Dumará, 1994, p. 51-78.

HABERMAS, J. A lógica das ciências sociais. Petrópolis: Vozes, 2009.

JOAS, H. O interacionismo simbólico. In: GIDDENS, A.; TURNER, J. (org) Teoria social hoje. São Paulo: Ed. Unesp, 1999, pp. 127-174

KAUTSKY, K. A Questão Agrária. São Paulo: Proposta Editorial, 1980.

KUHN, T. S. A Estrutura das Revoluções Científicas. São Paulo: Perspectiva, 2003.

LAKATOS, I.; MUSGRAVE, A. A crítica e o desenvolvimento do conhecimento. São Paulo: Cultrix, 1979.

LAMARCHE, H. (org.) Produção familiar. Campinas: UNICAMP, 1993.

LAMRACHE, H. (Org.) L'agriculture familiale: du mythe à la réalité. Paris: L'Harmattan, 1994.

LÉFÈBVRE, H. Problemas de sociologia rural. In: MARTINS, J. S. (org). Introdução crítica à sociologia rural. São Paulo: Hucitec, 1986, pp. 144-163.

LÊNIN, W. O Desenvolvimento do Capitalismo na Rússia. São Paulo: Abril Cultural, 1984. 
LIMA, E. G. Bamburristas da Terra da Opala: identidade sócio-cultural e os desafios frente a políticas de inserção produtiva em Pedro II-PI. Dissertação de Mestrado. Programa de PósGraduação em Políticas Públicas. Universidade federal do Piauí. Teresina: UFPI, 2008.

MALUF, R. S. et al. O enfoque da multifuncionalidade da agricultura: aspectos analíticos e questões de pesquisa. I Seminário de pesquisa sobre estratégias de desenvolvimento, multifuncionalidade da agricultura e agricultura familiar no Brasil. Rio de Janeiro: CPDA/UFRRJ, 2002, 15 p.

MALUF, R.S. Políticas Agrícolas e de Desenvolvimento Rural e a Segurança Alimentar. In: LEITE, S. (org.). Políticas públicas e agricultura: Estado e desenvolvimento rural no Brasil do final do século XX. Porto Alegre: UFRGS, 2001.

MALUF, R.S. Segurança Alimentar e Desenvolvimento Econômico na América Latina: o Caso do Brasil. Revista de Economia Política, S. Paulo, 15(1-57), 1995, 134-140.

MANNHEIM, K. O pensamento conservador. In: MARTINS, J. S. (org). Introdução crítica à sociologia rural. São Paulo: Hucitec, 1986, pp. 77-134.

MARTINS, J. S. (org). Introdução crítica à sociologia rural. São Paulo: Hucitec, 1986.

MARTINS, J. S. Capitalismo e tradicionalismo: estudos sobre as contradições da sociedade agrária no Brasil. São Paulo: pioneira, 1975.

MARTÍNS, T. I. Palheiros/as da carnaúba em Campo Maior -PI: uma etnografia. Dissertação. Programa de Pós-Graduação em Antropologia e Arqueologia. Universidade Federal do Piauí. Teresina: UFPI, 2012.

MARTÍNS, T. I.; MORAES, M. D. O Trabalho dos Cortadores de "Palha" no Agronegócio da Carnaúba no Estado do Piauí. 27ª Reunião Brasileira de Antropologia, Belém - PA, de 1 a 4 de agosto, 2010. CD-ROM.

MASUlO, P. M. N. Trabalho escravo e agronegócio no Piauí: Uma análise da situação a partir dos anos 1990. Projeto de pesquisa. Programa de Programa de Pós-Graduação em Sociologia. Universidade Federal do Piauí. 2013. 18 p

MATOS, S. O. Povos e territórios quilombolas das Lagoas: uma etnografia (a construção da territorialidade quilombola em Lagoas-PI). Texto de Dissertação de Mestrado aprovado em Exame de Qualificação. Programa de Pós-Graduação em Antropologia e Arqueologia. Universidade Federal do Piauí. Teresina: UFPI, 2013.

MATTEI, L. Agroturismo: situação e perspectivas no Estado de Santa Catarina. ANAIS... XXXVIII Congresso Brasileiro de Economia e Sociologia Rural, Rio de Janeiro: IRSA/SOBER, 2000, CD Rom.

MAY, T. Pesquisa documental; escavações e evidências. In: Pesquisa social - questões, métodos e processos. Porto Alegre: Artmed, 2004, pp. 205-230

MENESES, M. A. Reciprocidade e campesinato. Campina Grande, 2007, 21 p

MINISTÉRIO DO DESENVOLVIMENTO SOCIAL E COMBATE À FOME; SECRETARIA NACIONAL DE SEGURANÇA ALIMENTAR E NUTRICIONAL. Edital 
MDS/SESAN N ${ }^{\mathbf{O}}$ 04/2011. Seleção pública de projetos de agricultura urbana e periurbana, 2011. Disponível em: http://www.mds.gov.br/segurancaalimentar/editais/2011/editais-20112/selecao-publica-de-projetos-de-agricultura-urbana-e-periurbana/arquivos/1edital-2011.pdf

MIRIM, L. V. L. Garimpando sentidos em bases de dados. In: SPINK, M. J (org.) Práticas discursivas e produção de sentido no cotidiano. São Paulo: Cortez Editora, 2000, pp.153181

MORAES, M. D. C. De Camponês a agricultor familiar: imagens do campesinato, como identidades na ordem da razão. Raízes, Campina Grande (PB), n. 17, junho/98, 121-134. (Edição especial).

MORAES, M. D. C. Le nouveau Nordeste des cerrados dans les nouvelles dynamiques territorialles. In: SABOURIN, E.; TEIXEIRA, O. (orgs.). Planification du développement territorial au Brésil, Montpelier: Cirad, 2002.

MORAES, M. D. C. Memórias de um sertão desencantado (modernização agrícola, narrativas e atores sociais nos cerrados do sudoeste piauiense). Tese (Doutorado em Ciências Sociais). Universidade Estadual de Campinas. Campinas: UNICAMP, 2000, 475 p.

MORAES, M. D. C. Ruralidades contemporâneas: qual o lugar da cultura? Uma análise do texto teórico brasileiro. Plano de trabalho para Estágio Pós-Doutoral. Versão preliminar. Teresina, 2013, $20 \mathrm{p}$.

MORAES, M. D. C. Ruralidades, campesinato, novo nominalismo: trilhas de um debate sobre o "rural" contemporâneo. ANAIS.... XXVIII CONGRESSO INTERNACIONAL DA ALAS. 6 a 11 de setembro de 2011, UFPE, Recife-PE. GT05 - Desenvolvimento rural, globalização e crises. $18 \mathrm{p}$.

MORAES, M. D. C. Um povo do cerrado entre baixões e chapadas (modo de vida e crise ecológica de camponeses/as nos cerrados do sudoeste piauiense). In: GODOI, E. P.; MENEZES, M. A.; MARINA, R. A. (orgs.) Diversidades de campesinatos: expressões e categorias. Vol II. Estratégias de reprodução social. São Paulo: Ed. Da Unesp/Brasília:NEAD, 2009, pp. 131-16

MORAES, M. D. C.; F. A. FRAZÃO e T. ROGÉRIO JR. Andando Pelo Mundo: significados da migração temporária do Piauí para a agroindústria canavieira paulista. In: NOVAES, J. R. P. e F. ALVES. (orgs.). Migrantes: trabalho e trabalhadores no complexo agroindustrial canavieiro (os heróis do agronegócio brasileiro). São Carlos-SP: EDUFSCar, 2007, pp. 257296.

MORAES, M. D. C.; MARTíNS, T. I. Cortadores de palha de carnaúba em Campo Maior PI: Trajetórias narradas e intersubjetividade na pesquisa com oralidades. VIII Encontro de história oral do Nordeste, CD ROM, Teresina, Piauí, 2011, 15 p.

MORAES, M. D. C.; PEREIRA, F. C. Imagens e narrativas do "rural" (sentidos de ruralidades na produção acadêmica da pós-graduação stricto senso na área de Ciências Humanas, da UFPI, da década de 1990 a 2010). Projeto de Pesquisa. Teresina, 2000, 20 p.

MORAES, M. D. C.; REIS, T. B. Corpos em transição (Campesinato, trabalho assalariado, meio ambiente de trabalho, disciplinamento e resistência, em empresas agropecuárias nos cerrados piauienses). $5^{\mathbf{O}}$ ENCONTRO DA REDE DE ESTUDOS RURAIS: 
"Desenvolvimento, ruralidades e ambientalização: atores e paradigmas em conflito". Belém, 03 a 06 de junho de 2012. 1 CD ROM.

MORAES, M. D. C.; VILELA, S. L. O. Multifuncionalidade e agricultura camponesa nos cerrados piauienses: desafios para a sustentabilidade. In: CARNEIRO, M. J., MALUF. R. (org.). Para além da produção. Multifuncionalidade e agricultura familiar. Rio de janeiro: MAUAD, 2003, pp. 102-122.

MORAES, M. D. C.; VILELA, S. L. Relatório de Pesquisa SAG-Carnaúba Teresina. [Vers. Prel.]. 2010.

MORIN, E. O pensamento dissimulado (paradigmatologia). In: O método 4. As idéias. Habitat, vida, costumes, organização. Porto Alegre: Sulina, 2001, pp. 258-295

NASCIMENTO, L. P. O S. Sentidos de lugar na relação rural-urbano - o caso de Lagoa da Mata, Teresina - PI. Projeto de pesquisa. Programa de Programa de Pós-Graduação em Sociologia. Universidade Federal do Piauí. 2013. 18 p.

NEVES, D. P. Constituição e reprodução do campesinato no Brasil: legado dos cientistas sociais. In: NEVES, D. P.; SILVA, M. A. M. (orgs). Processos de constitituição e reprodução do campesinato no Brasil. Vol. 2. Formas dirigidas de constituição do campesinato. São Paulo: Ed. Da Unesp/Brasília:NEAD, 2009, pp. 303-326

NEVES, D. P. Formas tuteladas de condição camponesa: colonato e morada na agroindustria exportatadora. In: NEVES, D. P.; SILVA, M. A. M. (orgs). Processos de constitituição e reprodução do campesinato no Brasil. Vol. 1. Formas tuteladas de condição camponesa. São Paulo: Unesp/Brasília:NEAD, 2008, pp. 137-161

NEVES, D. P. O econômico e o familiar: interdependências, potencialidades e constrangimentos. In: MOTA, D. M. et al. (Ed.) Agricultura familiar: desafios para a sustentabilidade (coletânea). Aracaju: Embrapa-CPATC, SDR/MA, 1998, p. 13-33.

NISBET, R. A. Conservadorismo e sociologia. In: MARTINS, J. S. (org). Introdução crítica à sociologia rural. São Paulo: Hucitec, 1986, pp. 62-66.

OLIVEIRA, A. M. S. Indicadores de sustentabilidade: uma proposta de tipologia de assentamentos rurais em Teresina/PI. 202f. Texto de qualificação para Tese de Doutorado. Programa de Pós-Graduação em Desenvolvimento e Meio Ambiente, Universidade Federal do Piauí, Teresina, 2013.

OLIVEIRA, M. V. Algodões I: um drama social (povos e territórios do Açude/Barragem Algodões I, em Cocal, no Piauí: processos, atores, narrativas). Dissertação de Mestrado. Programa de Pós-Graduação em Antropologia e Arqueologia. Universidade Federal do Piauí. Teresina: UFPI, 2013.

OLIVEIRA, R. C. Identidade étnica e a moral do reconhecimento. Caminhos da identidade. Ensaios sobre etnicidade e multiculturalismo. São Paulo/Brasília: UNESP/Paralelo 15, 2006, pp. 19-58.

PAOLIELlO, R. M. Condição camponesa e novas identidades entre remanescentes de quilombos no Vale do Ribeira e Iguape. In: GODOI, E. P.; MENEZES, M. A.; MARINA, R. 
A. (orgs.) Diversidades de campesinatos: expressões e categorias. Vol I. Construções identitárias e sociabilidades. São Paulo: Ed. Da Unesp/Brasília:NEAD, pp. 229-250.

PEREIRA, F. C. A sustentabilidade da agricultura familiar no Vale do Gurgueia-PI: construção de novas identidades socioprofissionais. Tese (Doutorado em Sociologia). Universidade Federal do Rio Grande do Sul, Porto Alegre, 2004.

PRADO, R. Todo ano tem. As festas na estrutura social camponesa. São Luiz: EDUFMA, 2007, pp. 45-129.

QUEIROZ, M. I. O campesinato brasileiro. Petrópolis: Vozes, 1973

REDCLIFF, M. R. Pós sustentabilidade e os novos discursos de sustentabilidade. Raízes, Campina Grande, vol. 21, n.1, pp. 124-136, jan/jun/2002.

REIS, T. B. Meio ambiente de trabalho rural (condições ambientais de trabalho agrícola nos cerrados piauienses) (2010). Dissertação de Mestrado em Desenvolvimento e Meio Ambiente- Rede PRODEMA-UFPI. Teresina: Universidade Federal do Piauí.

REIS, T. B. Campesinato nos cerrados piauienses, trabalho infantil e políticas públicas: encontros, desencontros na arena das legimidades. 2012, 15 p. Projeto de Pesquisa/Doutorado. Programa de Pós-Graduação em Políticas Públicas, Universidade Federal do Piauí. Teresina: UFPI, 2013.

REIS, T. B.; MORAES, M. D. C. Meio ambiente de trabalho em empresas agropecuárias nos cerrados piauienses: disciplinamento do corpo e resistência de trabalhadores/as rurais. Revista Jurídica da Presidência/ Centro de estudos jurídicos da presidência. Vol. 13, n. 99, fevereiro-maio 2011. Quadrimestral. Disponível em HTTP://presidência.org.br/revistajuriciaRIBEIRO, G. L. Ambientalismo e desenvolvimento sustentado. Nova ideologia/utopia do desenvolvimento. Brasília: UnB, 1992, mimeo, 55 p.

REIS, T. B.; MORAES, M. D. C. Trabalhadores/as e meio ambiente de trabalho rural em empresas agropecuàrias nos cerrados piauienses. XV ENCONTRO DE CIENCIAS SOCIAIS DO NORTE E NORDESTE PRÉ-ALAS BRASIL. 04 a 07 de setembro de 2012, UFPI, Teresina-PI. 1 CD ROM.

ROGÉRIO JR., T. "A gente leva o dinheiro, mas fica o couro" (Migração temporária de camponeses para o Trabalho no corte de cana, adoecimento, morte, e Políticas de proteção social: o caso de Elesbão Veloso - PI). Dissertação. Programa de Pós-Graduação em Políticas Públicas. Universidade Federal do Piauí. Teresina, 2010.

ROMEIRO, A. R. Meio Ambiente e Produção Familiar na Agricultura In: Agricultura Familiar. Desafios e Sustentabilidade. Brasília: SDR/EMBRAPA, 2000.

ROSA, P. P. V. Políticas públicas em agricultura urbana e periurbana no Brasil. Revista Geográfica de América Central. Número especial. Costa Rica, 2011. 17 p. http://www.revistas.una.ac.cr/index.php/geografica/article/view/2384

RUBEN, G. R. Teoria da identidade: uma crítica. Anuário Antropológico/86. Brasília: UnB/Tempo Brasileiro, 1988, pp. 77-93. 
RUBERT, R. A.; SILVA, P. S. O acamponesamento como sinônimo de aquilombamento: o amálgama entre resistência racial e resistência camponesa em comunidades negras rurais do rio Grande do Sul. In: GODOI, E. P.; MENEZES, M. A.; MARINA, R. A. (orgs.) Diversidades de campesinatos: expressões e categorias. Vol I. Construções identitárias e sociabilidades. São Paulo: Ed. Da Unesp/Brasília:NEAD, pp. 251-274..

SANTOS, B. S. Introdução a uma ciência pós-moderna. Rio de Janeiro: Graal, 1989.

SANTOS, G.; MORAES, M. D. C. A arte de "botar boi" no Território Palmares, LuzilândiaPI. XV ENCONTRO DE CIENCIAS SOCIAIS DO NORTE E NORDESTE P PREALAS BRASIL. Universidade Federal do Piauí - UFPI, Teresina-Piauí, 04 a 07 de setembro de 2012.

SARACENO, E. La experiência europea de desarrolo rural y su utilidad para el contetxo latinoamericano. Seminário Internacional sobre Agricultura Familiar Sustentável, de 21 a 23/1 de 2001 Brasília-DF. (D/700440). Mimeo, 9 p.

SCHNEIDER, S. Agricultura Familiar e Industrialização. Pluriatividade e Descentralização Industrial no Rio Grande do Sul. Porto Alegre, Ed. UFRGS, 1999.

SHANIN, T. A definição de camponês: conceituações e desconceituações. In: Estudos CEBRAP, São Paulo, n. 26, p. 41-80, 1980.

SHANIN, T. Lições camponesas. In: PAULINO, E. T.; FABRINI, J. E. (org.) Campesinato. Territórios em disputa. São Paulo: expressão popular, 2008, pp. 23-47.

SILVA, J. G. O Novo Rural Brasileiro. Campinas, São Paulo: Unicamp/I.E. Coleção Pesquisas, 1999.

SILVA, M. V. Pisando em terra firme(?): identidades juvenis e reprodução social na localidade rural Roça Nova, Sebastião Leal-PI Relatório final de Estágio Pós-Doutoral. Programa de Pós-Graduação de Ciências Sociais, em Desenvolvimento, Agricultura e Sociedade-CPDA, da Universidade Federal Rural do Rio de Janeiro-UFRRJ. Rio de Janeiro, 2011.

SOUSA, M. S. R. Imaginário social de semi-árido e o processo de construção de saberes ambientais: o caso do município de Coronel José Dias-Piauí. Dissertação de Mestrado em Desenvovolvimento Meio Ambiente. Teresina: UFPI, 2005.

SOUSA, M. S. R.; PEREIRA, R. A.; PAZ, F. P. C. Inventário de comunidades Quilombolas no Piauí. Mesa-Redonda, Encontro Estadual da ANPUH, Caxias-MA, set./2010, 18 p.

SOUZA, C. V. A pátria geográfica: sertão e litoral no pensamento social brasileiro. Goiânia: UFG, 1997.

SPINK, P. Análise de documentos de domínio público. In: SPINK, M. J (org.) Práticas discursivas e produção de sentido no cotidiano (org). São Paulo: Cortez Editora, 2000, pp. 123-151.

VEIGA, J. E. et all. O Brasil Rural precisa de uma estratégia de desenvolvimento. Brasília: CNDRS/MDA/NEAD, 2001. (Texto provisório para discussão). 
VILELA, S, L. O. O meio rural piauiense na virada do século: novos processos, novos atores e novas oportunidades. In: CAMPANHOLA, C.; SILVA, J. G. (org.) O novo rural brasileiro. Uma análise estadual - Nordeste. V. 2. Jaguariúna: Embrapa meio Ambiente, 2000b, pp. 45-69

VILELA, S. L O.; MORAES, M. D. C. Relatório de Pesquisa SAG-Babaçu. Teresina, set./ 2008. $85 \mathrm{p}$.

VILELA, S. L. O. A importância das novas atividades agrícolas ante a globalização: a apicultura no Estado do Piauí. Teresina, 2000a.

VILELA, S. L. O. La teritorialité des nouvelles activités agricoles dans 1'Étatt du Piauí. In: SABOURIN, E.; TEIXEIRA, O. (orgs.). Planification du développement territorial au Brésil, Montpelier: Cirad, 2002, pp. 53-62.

VILELA, S. L. O.; MORAES, M. D. C. Agricultura urbana e periurbana (uma abordagem territorial a partir da experiência do município de Teresina-PI, Brasil). VI Congresso Internacional Sistemas Agroalimentares Localizados. Florianópolis, de 21 a 25 de Maio/2013

VIOLA, E. J. et al. Meio ambiente, desenvolvimento e cidadania: desafios para as ciências sociais. São Paulo: Cortez, 2001.

WANDERLEY, M. B. W. A ruralidade no Brasil moderno. Por um pacto social pelo desenvolvimento rural. In: ¿Una nueva ruralidad en América Latina? Norma Giarracca. CLACSO, Consejo Latinoamericano de Ciencias Sociales, Ciudad Autónoma de Buenos Aires, Argentina. 2001, pp. 31-44. Disponivel em: http://bibliotecavirtual.clacso.org.ar/ar/libros/rural/wanderley.pdf .Acessado em janeiro de 2002.

WANDERLEY, M. N. B. A emergência de uma nova ruralidade nas sociedades modernas avançadas - o "rural" como espaço singular e ator coletivo. Estudos Sociedade e Agricultura, 15, outubro 2000, pp. 87-145.

WANDERLEY, M. N. B. A sociologia rural na América Latina: produção de conhecimento e compromisso com a sociedade. Disponível em: http://www.alasru.org/wpcontent/uploads/2011/06/Nazareth-Wanderlei.pdf; Acessado em julho julho/2011

WANDERLEY, M. N. B. Raízes históricas do campesinato brasileiro. XX ENCONTRO ANUAL DA ANPOCS. GT 17. PROCESSOS SOCIAIS AGRÁRIOS. CAXAMBU, MG. OUTUBRO 1996, $21 \quad$ p. $\quad$ Disponível http://agriculturasamazonicas.ufpa.br/PDF'S/AA_selecao/2011/Wanderley\%201996.pdf

WANDERLEY, M. N. B.; LOURENÇO, F. A. O agricultor familiar e a sociabilidade no espaço local. Notas sobre um estudo comparativo internacional. XVII Encontro nacional do PIPSA, IFCH/UFRGS, Porto Alegre, novembro, 1994.

WOLF, E. Tipos de campesinato latino-americano: uma discussão preliminar. In: FELDMAN-BIANCO, B.; RIBEIRO, G. L. (Org.). Antropologia e poder. Brasília: EdUnB, Campinas: Editora da Unicamp, 2003, pp.117-144.

WOORTMann, E. Teorias do campesinato. In: Herdeiros, Parentes e compadres. São 
Paulo-Brasília/Hucitec-Edunb, 1995, pp. 30-66.

WOORTMANN, k. Com parente não se neguceia. In: Anuário Antropológico, Brasília:UnB, 1990, pp.11-73. 